\title{
The Effect of Titanium Nano Oxide and Heat Treatment on Physical Properties of Hornbeam (Carpinus betulus) in Golestan Province
}

\author{
Fatemeh Dehghanian*, Seyyed Mahmood Kazemi, Maryam Ghorbani Kokandeh \\ Department of Wood and Paper Sciences, Faculty of Natural Resources, Sari Agricultural Sciences and Natural Resources \\ University, Mazandaran Province, Sari, Iran \\ Email: ^ fatemehdehghaniyan27@gmail.com
}

How to cite this paper: Dehghanian, F., Kazemi, S.M. and Kokandeh, M.G. (2020) The Effect of Titanium Nano Oxide and Heat Treatment on Physical Properties of Hornbeam (Carpinus betulus) in Golestan Province. American Journal of Plant Sciences, 11, 1601-1611.

https://doi.org/10.4236/ajps.2020.1110115

Received: July 27, 2020

Accepted: October 24, 2020

Published: October 27, 2020

Copyright $\odot 2020$ by author(s) and Scientific Research Publishing Inc. This work is licensed under the Creative Commons Attribution International License (CC BY 4.0).

http://creativecommons.org/licenses/by/4.0/

(c) (i) Open Access

\begin{abstract}
The use of wood has been considered for a long time and to this day, it has a special place in human life. Modification of wood and lignocellulosic materials is done by various methods, including modification of physical, mechanical, chemical and thermal, that as a new technology, it leads to the improvement of their undesirable features. Among these methods, heat correction is a useful method to improve dimensional stability and leads to increased resistance to water absorption and decay. The main purpose of this study is to investigate the titanium Nano oxide and heat treatment on the physical properties of hornbeam species. Samples were saturated with titanium Nano oxide solution at a concentration of $5000 \mathrm{ppm}$ and pressurized 7 times in a pressure tank. The samples were divided into three groups: control, heat and Nano thermal treatment. Heat and saturated samples with titanium Nano oxide were heat treated at three temperature levels of $150^{\circ} \mathrm{C}, 175^{\circ} \mathrm{C}$ and $200^{\circ} \mathrm{C}$ for 4 and 6 hours. All three groups underwent physical tests. Heat and Nano thermal oxide treatments led to reduced water absorption and thickness swelling. Comparison between heat and Nano thermal treatment showed a further decrease in water absorption and thickness swelling in Nano thermal samples.
\end{abstract}

\section{Keywords}

Heat Treatment, Physical Properties, Titanium Nano Oxide, Hornbeam

\section{Introduction}

Among different broadleaf species in the northern forests of Iran, hornbeam (Carpinus betulus) is one of the most important forest species, which have a 
wide range of distribution and cover a significant percentage of the northern forests. This species constitutes about $30 \%$ to $40 \%$ of the total commercial forests in the north of the country [1].

Hornbeam wood is heavy, hard with a specific gravity between 0.8 to $1 \mathrm{gr} / \mathrm{cm}^{3}$. The shrinkage of this wood is high and it cracks quickly. These woods should be converted as soon as possible or kept saturated [2].

Nanotechnology is a general term that refers to all advanced technologies in the field of Nano scale work. Nanoparticles are nanometer-sized particles. Nanoparticles can be composed of different materials, such as metal or ceramic. Treatment temperature and time are the most important factors in the heat treatment process. Nanoparticles such as titanium dioxide $\left(\mathrm{TiO}_{2}\right)$ and zinc oxide $(\mathrm{ZnO})$ are good materials in wood protection by preventing the proliferation of destructive agents in wood and wood composites. Also, impregnation with metal Nano-oxides, due to their high thermal conductivity, transfers heat to the depths of wood under heat treatment and intensifies the treatment [3].

Extensive research has been done on the effect of heat on wood and it has been proven that heat correction is a useful method to improve dimensional stability and increase decay resistance. Also, research has been done on the effect of heat on the mechanical strength of wood [4].

\subsection{Moisture Content}

Wood moisture content is significantly reduced by heat treatment. This decrease is related to the time and temperature of the treatment process as well as to atmospheric pressure. Wood adsorption reactions were investigated by heat treatment in the presence or absence of air (oxygen) and they found that the moisture absorption capacity decreased with increasing time and treatment temperature [5].

Seborg (1953) [6] found that the moisture content of modified pine wood with heat at $300^{\circ} \mathrm{C}$, was reduced by about $90 \%$ compared to untreated wood and with a longer heating period, the moisture content decreases further.

Stamm and Hansen (1973) [7] showed that at temperatures above $205^{\circ} \mathrm{C}$, there was a decrease in moisture content. Heat correction at temperatures varies between 180 and 260 in practice. At temperatures below $140^{\circ} \mathrm{C}$, there are slight changes in the properties of the wood material and at temperatures above $140^{\circ} \mathrm{C}$ leads to the destruction of the middle layers.

Schneider and Rosche (1973) [5] found that the adsorption capacity decreased with increasing treatment time and treatment temperature. However, when the samples were heat-treated in the presence of air at $200^{\circ} \mathrm{C}$, adsorption capacity increased with the extension of the treatment period ( 24 hours for pine and 48 hours for spruce according to tissue reduction of about 20\%). Also, there has been a relationship between the relative reduction of wood texture due to heat treatment and the reduction in adsorption capacity for treatment in the presence of air. However, this treatment showed a further reduction in beech uptake 
compared to Christmas.

\subsection{Dimensional Stability}

When wood is modified, its dimensional stability increases but the effect of correction depends on its variables [8]. Increased ASE was reported by needle-leaf specimens due to temperature treatment and time. For example, an ASE of $20 \%$ is evident by heating wood samples at $150^{\circ} \mathrm{C}$ for 6 days or at $250^{\circ} \mathrm{C}$ for $30 \mathrm{mi}$ nutes that maximum ASE occurs with $20 \%$ weight loss [7].

Millett and Gerhards (1972) [9] investigated the effect of different treatment times and temperatures on tissue reduction in heat treatment. They stated that with increasing heat and treatment time, we will have more wood texture reduction.

Chang and Keith (1978) [10] investigate the elongation of wood due to heat treatment and its relationship with the reduction of wood texture due to heat treatment. They stated that there was a slight increase in the longitudinal dimensions due to the effect of the radial and longitudinal tensile interaction. Dirol and Guyonnet (1993) [11] reported that thermal modification at high temperatures on pine and spruce species reduced dimensional and radial.

Dehmardeh (2011) [12] reported that during heat treatment of hornbeam species at $130^{\circ} \mathrm{C}, 160^{\circ} \mathrm{C}$ and $190^{\circ} \mathrm{C}$ for 3 and $9 \mathrm{~h}$, the maximum weight loss was at $190^{\circ} \mathrm{C}$ and the minimum weight loss was at $130^{\circ} \mathrm{C}$ for $3 \mathrm{~h}$. The highest dimensional stability was observed at $190^{\circ} \mathrm{C}$ for $9 \mathrm{~h}$.

Sahin and Mantanis (2011) [13] investigated the effect of treatment with titanium dioxide and zinc nanoparticles on swelling, water absorption and extrinsic hardness of chestnut, cherry, fir and black pine. Swelling of treated and untreated samples after 5 minutes of immersion in distilled water at $23^{\circ} \mathrm{C}, 50^{\circ} \mathrm{C}$, $75^{\circ} \mathrm{C}$ and $100^{\circ} \mathrm{C}$, showed that nanoparticles are an effective factor in reducing swelling. The highest swelling improvement was obtained at $23^{\circ} \mathrm{C}$ and the swelling improvement was different for different species (56.1\% male, $47.6 \%$ pine, $30.7 \%$ chestnut and $20.4 \%$ cherry). As the water temperature increased, the swelling rate of treated and untreated samples increased; however, the swelling of the treated samples was still less than the untreated samples. The changes in the swelling of the samples were attributed to the reduction of the surface energy of the wood molecules due to the treatment with nonmaterial and it was stated that: When sufficient energy is provided in the water and wood system as the temperature and time increase, Also the bond between the nonmaterial and the wood is broken; As a result, swelling increased.

\section{Materials and Methods}

\subsection{Preparing Test Samples}

The test sample is hornbeam wood (carpinu sbetulus) which was obtained from the forests of Shastoklate located $12 \mathrm{~km}$ southwest of Gorgan (Iran). Shast Kalateh Educational and Research Forest of Gorgan are located in the northern 
slopes of the Alborz mountain range. This mountain range extends east-west to the south of the Caspian Sea. This forest is located at latitude 36 degrees and 41 minutes to 36 degrees and 45 minutes north and longitude 54 degrees and 20 minutes to 54 degrees and 24 minutes east.

The height of the place where the trees grew was about 250 to 300 meters above sea level. Three 1-meter-long nostrils with a diameter equal to the chest of about $20-30 \mathrm{~cm}$ were randomly selected and transferred to the university after cutting. The sample woods were placed in the carpentry environment of the university for about 1 month to reduce their moisture. Their skins were then peeled off with a hand tool and cut with a band saw. Samples were prepared according to the standard from non-knotted wood and fungal degradation.

The samples were marked and numbered as shown in Table 1 as treatment codes. Healthy samples were dried in an oven at $103^{\circ} \mathrm{C}$ for 24 hours to reduce their humidity to zero. After balancing, the samples were placed in a desiccator for 15 minutes and then weighed.

\subsection{Saturation of Wood with Titanium Nano Oxide}

At this stage, the wood samples were saturated with the final vacuum filled cell method with a suspension of titanium Nano oxide at a concentration of 5000 ppm by a cylinder in the laboratory of the Faculty of Wood. For saturation, the samples were first placed in a suitable container and restrained by weights to prevent them from floating when the protective liquid entered. The container containing the samples was placed in the saturated container just below the liquid inlet valve. To expel the air inside the samples and the initial vacuum was applied for 15 minutes under negative pressure 0.7. At the end of the vacuum step, the protective liquid was injected into the samples by opening the valve on the saturation tank. The treatment solution was poured into a container until it covered the samples. Then in the next step, a pressure equal to 7 was applied for 120 minutes. The samples were removed from the protective material and dried on them with an additional solution cloth.

\subsection{Heat Treatment}

After drying the saturated samples in titanium Nano oxide solution, the samples were treated with the control samples for 4 and 6 hours at $150^{\circ} \mathrm{C}, 175^{\circ} \mathrm{C}$ and

Table 1. Treatment codes of wood samples.

\begin{tabular}{|c|c|c|c|c|c|c|c|}
\hline Treatment & control & H-150-4 & H-150-6 & H-175-4 & H-175-6 & H-200-4 & H-200-6 \\
\hline code & $\begin{array}{l}\text { No heat and } \\
\text { Nano treat }\end{array}$ & $\begin{array}{l}\text { Sample Heat } \\
150^{\circ} \mathrm{C}-4 \mathrm{~h}\end{array}$ & $\begin{array}{l}\text { Sample Heat } \\
150^{\circ} \mathrm{C}-6 \mathrm{~h}\end{array}$ & $\begin{array}{l}\text { Sample Heat } \\
175^{\circ} \mathrm{C}-4 \mathrm{~h}\end{array}$ & $\begin{array}{l}\text { Sample Heat } \\
175^{\circ} \mathrm{C}-6 \mathrm{~h}\end{array}$ & $\begin{array}{l}\text { Sample Heat } \\
200^{\circ} \mathrm{C}-4 \mathrm{~h}\end{array}$ & $\begin{array}{l}\text { Sample Heat } \\
200^{\circ} \mathrm{C}-6 \mathrm{~h}\end{array}$ \\
\hline Treatment & $\mathrm{N}$ & NH-150-4 & NH-150-6 & NH-175-4 & NH-175-6 & NH-200-4 & NH-200-6 \\
\hline code & unread samples & $\begin{array}{c}\text { Sample Nano } \\
\text { thermal oxide } 1 \\
150^{\circ} \mathrm{C}-4 \mathrm{~h}\end{array}$ & $\begin{array}{c}\text { Sample Nano } \\
\text { thermal oxide } 1 \\
150^{\circ} \mathrm{C}-6 \mathrm{~h}\end{array}$ & $\begin{array}{c}\text { Sample Nano } \\
\text { thermal oxide } 1 \\
175^{\circ} \mathrm{C}-4 \mathrm{~h}\end{array}$ & $\begin{array}{l}\text { Sample Nano } \\
\text { thermal oxide } 1 \\
175^{\circ} \mathrm{C}-6 \mathrm{~h}\end{array}$ & $\begin{array}{l}\text { Sample Nano } \\
\text { thermal oxide } 1 \\
200^{\circ} \mathrm{C}-4 \mathrm{~h}\end{array}$ & $\begin{array}{c}\text { Sample Nano } \\
\text { thermal oxide } 1 \\
200^{\circ} \mathrm{C}-6 \mathrm{~h}\end{array}$ \\
\hline
\end{tabular}


$200^{\circ} \mathrm{C}$. Both groups of titanium Nano oxide-saturated samples and heat-treated samples were randomly placed in the oven. After the treatment and turning off the oven, the samples were taken out of the oven after one day without opening the oven door. After 24 hours, the samples were taken out of the oven and kept in room conditions for two weeks after weighing (Temperature $30^{\circ} \mathrm{C}$ and relative humidity $45 \%$ to $50 \%)$.

\subsection{Measurement of Physical Properties of Samples}

According to ASTM-D4442 standard, samples with dimensions of $2 \times 2 \times 2 \mathrm{~cm}$ were prepared. Linear measurements were performed in longitudinal (L), radial $(\mathrm{R})$ and tangential $(\mathrm{T})$ directions. Then the wet volume and weight were measured using a caliper with an accuracy of $0.02 \mathrm{~mm}$ and a digital scale with an accuracy of $0.001 \mathrm{~g}$. In the next step, the samples were dried in an autoclave for 24 hours at $103^{\circ} \mathrm{C} \pm 2^{\circ} \mathrm{C}$.

The volume and weight of the samples were determined in the dry state. The samples were immersed in a container containing water and after 2 and 24 hours, out of water and after drying on paper, the saturation volume of the samples was measured and recorded by a caliper. At the end of the linear swelling in the longitudinal, tangential, radial directions and the amount of water absorption after the mentioned times were calculated using the following equations:

$$
A b s=\left(W_{2}-W_{1}\right) / W_{1} \times 10
$$

Abs $=$ Absorbed water (\%).

$W_{2}=$ Wet weight after 2 and 24 hours of immersion in water (g).

$W_{1}=$ dry weight before immersion $(\mathrm{g})$.

Using the formula, linear swelling instead of $\mathrm{V}$ used $\mathrm{A}, \mathrm{R}$ and $\mathrm{T}$, which represent axial (longitudinal), radial, and tangential swelling, and the percentage of swelling in these directions was calculated.

\section{Results and Discussion}

The results showed that the weight loss due to heat treatment in Nano thermal oxide samples is more than heat treatment. Also, water absorption and thickness swelling in Nano thermal oxidel samples were less than heat treatment and in recent samples it was more than the control. In general, it can be said that with increasing temperature and duration of treatment, the amount of water absorption decreased.

\subsection{Weight Loss}

The average percentage of weight loss obtained in different treatments is shown in Figure 1. As can be seen in the figure, there is a significant difference between treatment levels.

The results showed that increasing the temperature of heat treatment caused more weight loss in the treated samples. On the other hand, increasing the treatment time from 4 to 6 hours at the same temperature also resulted in more 


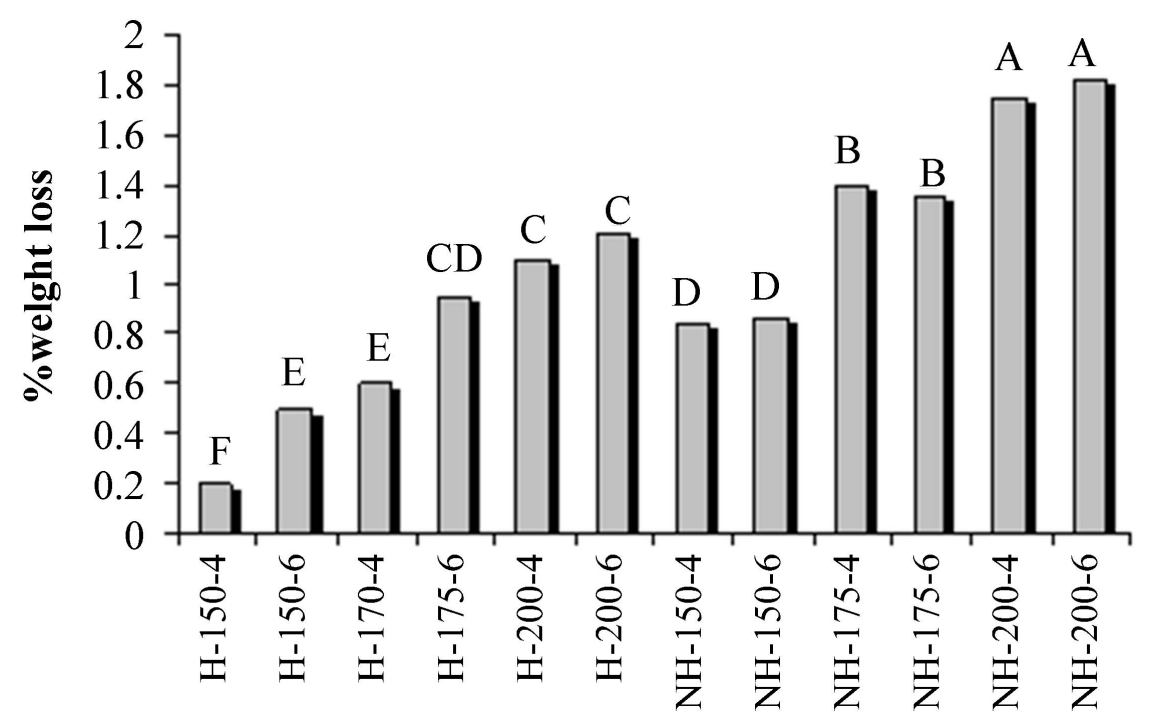

Figure 1. Weight loss of samples after heat treatment $(\mathrm{H}$ : heat treatment; $\mathrm{NH}$ : Nano thermal oxide treatment; 150, 175 and 200 temperatures of heat treatment; 4 and 6 hours duration of heat treatment per hour).

weight loss. Treatment of samples with titanium Nano oxide increased the intensity of weight loss of samples due to heat treatment. The difference in weight loss at higher temperatures is less than at lower temperatures, which was also observed in samples saturated with titanium Nano oxide.

\subsection{Water Absorption}

The results of comparing the means of water absorption index showed that with increasing the duration of treatment, there was a significant difference between the samples treated with each other and with the control (Figure 2).

The results of this study (Figure 2) showed that heat treatment reduced water absorption in the samples. With increasing the temperature of heat treatment, the water absorption capacity of the samples decreased significantly. On the other hand, increasing the heat treatment time from 4 to 6 hours at the same temperature also intensified the decrease in water absorption in the samples. Also, treatment of the samples with Nano titanium before heat treatment caused a further decrease in the hydrophilicity of the samples.

In non-written samples, 2 hours of immersion is not significantly different from the control sample, but in 24 hours of immersion is a significant difference. The decrease in water absorption decreased at different times with increasing treatment temperature and saturation with Nano titanium. The highest decrease in water uptake was in the Nano thermal oxide sample at $200^{\circ}-6$ hours, which decreased by $65.32 \%$ compared to the control.

Increased water absorption never indicates more moisture absorption in the cell wall; this is because crosslinking occurs in cell wall polymers and the sites of moisture absorption are reduced but the free water in the cavity is increased. Further weight loss, water uptake and thickness swelling in samples saturated 


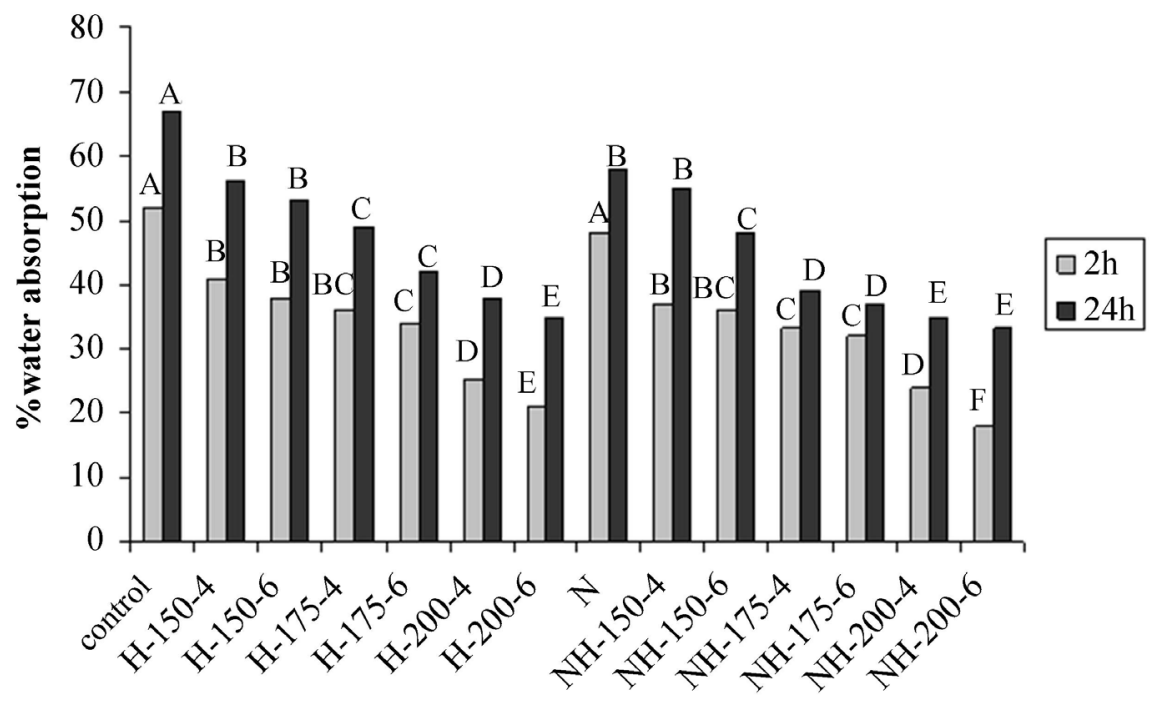

Figure 2. Water uptake of control, heat and Nano thermal samples of hornbeam species after 2 and 24 hours (H: heat treatment; NH: Nano thermal treatment; 150, 175 and 200 temperatures of heat treatment; 4 and 6 hours of heat treatment per hour).

with titanium Nano oxide solution indicate high thermal conductivity of titanium Nano oxide in saturated wood samples [14].

This leads to an increase in the process of degradation and pyrolysis of wood structure in the inner parts of the samples, which has led to further weight loss of Nano thermal oxide treatment samples [15].

\subsection{Longitudinal Swelling}

The results of comparing the mean in the longitudinal swelling index showed that with increasing the treatment time, there was a significant difference between the treated samples with other treatments and the control. The effect of heat treatment on saturated and unsaturated samples with Nano titanium is shown in Figure 3.

According to the results of Figure 3, it can be stated that the heat-treated samples showed smaller dimensional changes compared to the control sample and with increasing duration from 4 to 6 hours, the rate of swelling decreased. There is no significant difference between Nano-samples and control samples. Also, no significant difference was observed in 4 and 6 hour Nano thermal samples and 6 hours heat samples.

\subsection{Radial Swelling}

The results of comparing the mean values of radial swelling show that with increasing the treatment time, there was a significant difference between the treated samples and the control (Figure 4).

Heat-treated samples showed smaller dimensional changes than the control sample. Also, Nano thermal oxide samples had more drop than heat treatment samples, but in Nano treatment samples no significant difference was observed with the control sample. 


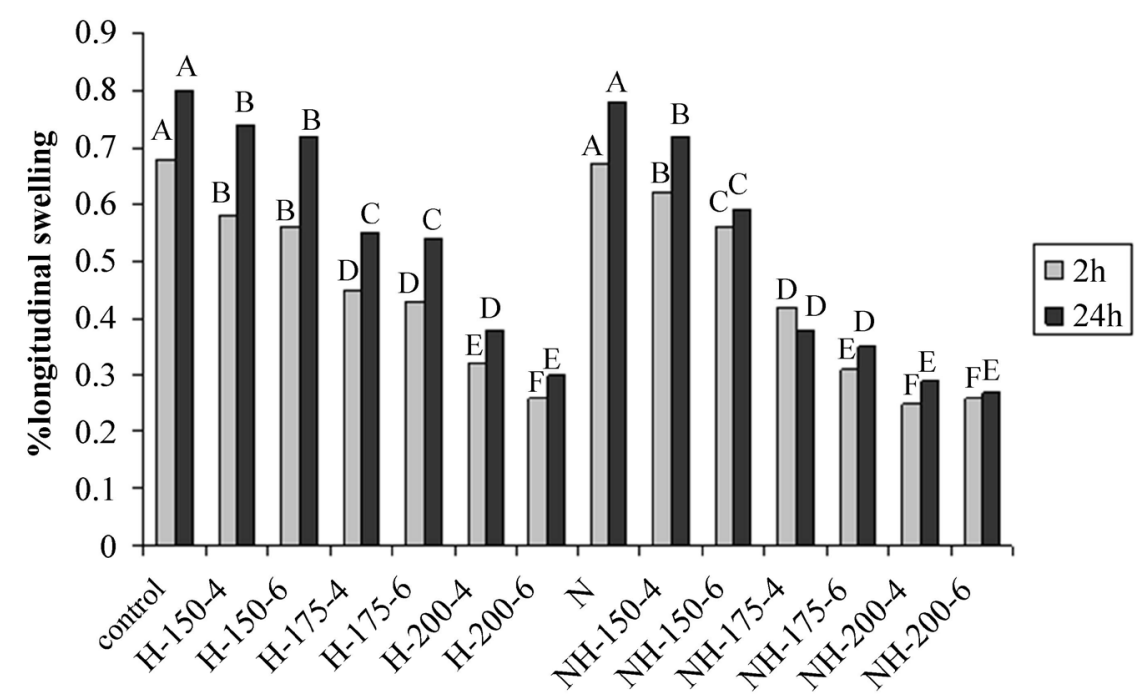

Figure 3. Longitudinal swelling of control, heat and Nano thermal samples after immersion in water for 2 and 24 hours (H: heat treatment; NH: Nano thermal treatment; 150, 175 and 200 heat treatment temperatures; 4 and 6 heat treatment times, respectively). The watch.

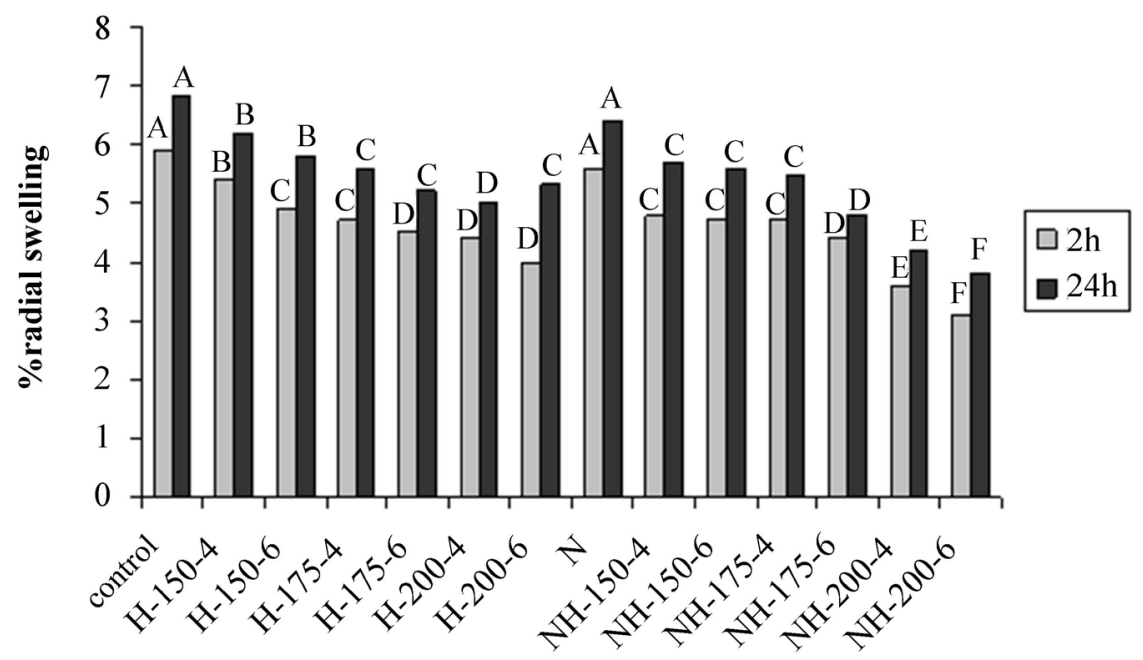

Figure 4. Radial swelling of control, heat and Nano thermal samples after 2 and 24 hours of immersion in water (H: heat treatment; NH: Nano thermal treatment; 150, 175 and 200 temperatures of heat treatment; 4 and 6 times of heat treatment on By hour).

Increasing the duration from 4 to 6 hours, the swelling decreased. The lowest swelling rate was after 2 and 24 hours of immersion and Nano heat samples at $200^{\circ} \mathrm{C}$ for 6 hours decreased compared to the control samples.

\subsection{Tangential Swelling}

The results of comparing the means for tangential swelling index showed that with increasing the duration of treatment, there was a significant difference between the samples treated with each other and with the control. The effect of heat treatment on Nano titanium saturated and unsaturated samples are shown in Figure 5. 


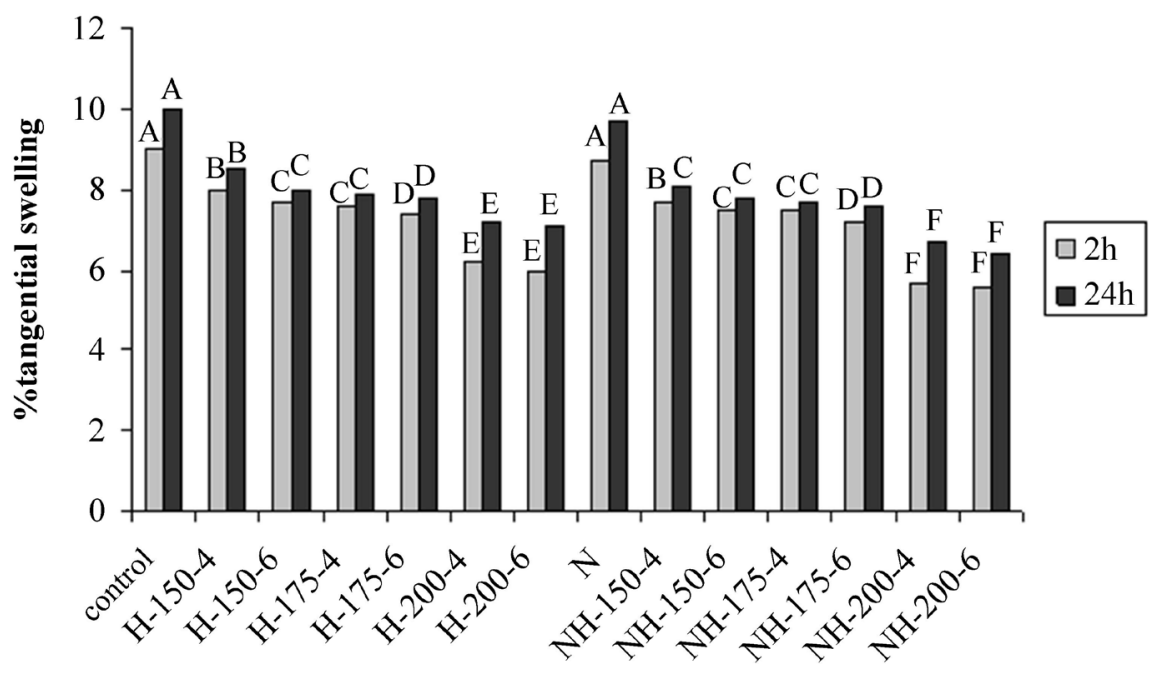

Figure 5. Mass swelling of the control samples, heat and Nano thermal after 2 and 24 hours of immersion in water ( $\mathrm{H}$ : heat treatment; $\mathrm{NH}$ : Nano thermal treatment; 150, 175 and 200 temperatures of heat treatment; 4 and 6 times of heat treatment In terms of hours).

The tangential swelling of the treated and control specimens are shown in Figure 5. Heat samples showed smaller dimensional changes compared to the control sample. Also, Nano thermal oxide samples had more reduction than heat treatment samples. But in samples treated with Nano significant reduction compared to control was observed. As the duration increased from 4 to 6 hours, the swelling decreased. The lowest swelling rate decreased after 2 and 24 hours of immersion in Nano heat samples at $200^{\circ}$ for 6 hours and 4 hours compared to the control samples.

The lower swelling and moisture content of high-temperature treated woods are attributed to the release of hemicellulose during heat treatment, the formation of cross-links between the reaction products of thermal decomposition, and the increased crystallinity of cellulose. Therefore, with the decomposition and removal of hemicellulose as a hydrophilic part of wood, dimensional stability increases. Lignin has the least chemical activity; but at high temperatures, the bonds between the lignin complexes also break to some extent and increase the concentration of hydrophobic phenolic groups [16]. In general, structural modification of hydrophilic wood polymers and possibly plasticization of lignin lead to reduced moisture and improved stability of wood dimensions [17].

The results of this study show that the thermal conductivity of metal nanoparticles, not only at high temperatures $\left(200^{\circ} \mathrm{C}\right)$, but also at lower temperatures $\left(150^{\circ} \mathrm{C}\right)$ that were previously thought to have little effect on physical and mechanical properties.

\section{Conflicts of Interest}

The authors declare no conflicts of interest regarding the publication of this paper. 


\section{References}

[1] Hosseinzadeh, A.S., Toghraei, N., Golbabaei, F. and Nourbakhsh, A. (2000) Investigation of Physical and Mechanical Characteristics of Hornbeam Species from Weiser Habitat of Mazandaran. Iranian Science, Wood and Paper Research, No. 9, 107-149.

[2] Parsa Pajooh, D. (2007) Wood Technology. University of Tehran Press, Tehran, 403 p.

[3] Shafizadeh, F. and Chin, P.P.S. (1977) Thermal Deterioration of wood. In: Goldstein, I.S., Ed., Wood Technology: Chemical Aspects, ACS Symposium Series, American Chemical Society, Washington DC, 57-81. https://doi.org/10.1021/bk-1977-0043.ch005

[4] Tiemann, H.D. (1915) The Effect of Different Methods of Drying on the Strength of Wood. Lumber World Review, 28, 19-20.

[5] Schneider, A. and Rusche, H. (1973) Sorption behaviour of beech and Spruce Wood after Heat Treatment in Air and in Vacuum. Holz als Roh- und Werkstoff, 31, 313-319. https://doi.org/10.1007/BF02607366

[6] Seborg, R.M., Tarkow, H. and Stamm, A.J. (1953) Effect of Heat upon the Dimensional Stabilization of Wood. Journal of the Forest Products Research Society, 3 , 59-67.

[7] Stamm, A.J. and Hansen, L.A. (1937) Minimizing Wood Shrinkage and Swelling. Effect of Heating in Various Gases. Industrial and Engineering Chemistry, 29, 831-833. https://doi.org/10.1021/ie50331a021

[8] Stamm, A.J., Burr, H.K. and Kline, A.A. (1946) Staybwood-Heat stabilized Wood. Industrial and Engineering Chemistry, 38, 630-634. https://doi.org/10.1021/ie50438a027

[9] Millett, M.A. and Gerhards, G.C. (1972) Accelerated Aging: Residual Weight and Flexural Properties of Wood Heated in Air at $115{ }^{\circ} \mathrm{C}$ to $175{ }^{\circ} \mathrm{C}$. Wood Science, 4, 193-201.

[10] Chang, C.I. and Keith, C.T. (1978) Properties of Heat-Darkened Wood. II. Mechanical Properties and Gluability. Report, Eastern Forest Products Laboratory, Canada, No. OPX214E.

[11] Dirol, D. and Guyonnet, R. (1993) The Improvement of Wood Durability by Retification Process. International Research Group on Wood Preservation, Doc. No. IRG/WP.

[12] Dahmardeh Ghalehno, M. (2011) Changes in the Physical and Mechanical Properties of Iranian.

[13] Sahin, H.T. and Mantanis, G.I. (2011) Nano-Based Surface Treatment Effects on Swelling, Water Sorption and Hardness of Wood. Maderas. Ciencia y Tecnología, 13, 41-48. https://doi.org/10.4067/S0718-221X2011000100004

[14] Jiji, L.M. (2009) Heat Conduction. 3rd Edition, Springer, Berlin, 412-416. https://doi.org/10.1007/978-3-642-01267-9

[15] Taghiyari, H.R. (2011) Study on the Effect of Nano-Silver Impregnation on Mechanical Properties of Heat-Treated Populus nigra. Wood Science and Technology volume, 45, 399-404. https://doi.org/10.1007/s00226-010-0343-5

[16] Tjeerdsma, B.F. and Militz, H. (2005) Chemical Changes in Hydrothermal Treated Wood: FTIR Analysis of Combined Hydro Thermal and Dry Heat-Treated Wood. Holz als Roh- und Werkstoff, 63, 102-111. 
https://doi.org/10.1007/s00107-004-0532-8

[17] Hakkou, M., Pétrissans, M., Gérardin, P. and Zoulalian, A. (2005) Investigation of Wood Wettability Changes during Heat Treatment on the Basis of Chemical Analysis. Polymer Degradation and Stability, 89, 1-5.

https://doi.org/10.1016/j.polymdegradstab.2004.10.017 